\title{
AS CIDADES NA CIVILIZAÇÃO ${ }^{1}$
}

JoÃo SARMENTO ${ }^{2}$

Em 1998, Sir Peter Hall, da Bartlett School of Architecture and Planning da Universidade de Londres, publicou no Reino Unido (WEIDENFELd \& Nicolson) um conjunto de cinco livros com o título As Cidades e a Civilização. Cultura, Inovação e Ordem Urbana ${ }^{3}$. Esta publicação, fruto de cerca de vinte anos de investigação primordialmente realizada nas bibliotecas da British Library e da Universidade da Califórnia em Berkeley, voltou a ser editada um ano mais tarde pela Pantheon, e é esta obra que aqui está em análise. Em parte pela sua extensão e abrangência de 2.500 anos de história e evolução das cidades, em parte pela densidade e detalhe do texto, só passados alguns anos me atrevi a fazer uma recensão.

Este conjunto de livros tem um tema comum, que se situa na esfera das cidades que em vários momentos do tempo e em várias localizações se mostraram particularmente inovadoras. A inovação urbana é desta forma a alma e fio condutor de todos os capítulos. As cinco partes abordam sub-temas da inovação urbana e têm extensões de certa forma desequilibradas. A primeira aborda a Cidade como Sublimação Cultural, analisando as cidades de Atenas (500-400 a.C.), Florença (1400-1500), Londres (1570-1620), Viena (1780-1910), Paris (1870-1910) e Berlim (1918-1933). A segunda, a Cidade como um Milieu Inovador, inclui as cidades de Manchester (1760-1830), Glasgow (1770-1890), Berlim (1840-1930), Detroit (1890-1915), a Região de São Francisco-Palo Alto-Berkeley (1950-1990) e o eixo Tóquio-Kanagawa (1890-1990). A terceira parte, bastante menos completa, debruça-se sobre a Aliança entre a Arte e a Tecnologia, e investiga as cidades de Los Angeles (1910-1945) e Memphis (1948-1956), sob a égide da invenção da cultura de massas. A quarta parte, refere-se ao Estabelecimento da Organização Urbana, sendo eleitas as cidades de Roma (50 a.C.-100 d.C.), Londres (1825-1900), Paris (1850-1870), Nova Iorque (1880-1940), Los Angeles (1900-1980), Estocolmo (1945-1980) e novamente Londres (1979-1993). Por fim, o 'quinto livro' - A União da Arte, Tecnologia e Organização, funciona como uma conclusão, onde HALL discursa, influenciado por MANUEL CASTELLS, sobre a passagem de uma Era Industrial para uma Era de Informação, e sobre as consequências da emergência de uma nova ordem urbana dominada pelas tecnologias

1 Hall, P. (1999) - Cities in Civilization. Culture, Innovation and Urban Order. Pantheon, Londres. 1169 p. (ISBN 0753808153 ).

2 Investigador no Núcleo de Investigação em Geografia e Planeamento da Universidade do Minho. Professor Auxiliar no Departamento de Geografia, Instituto de Ciências Sociais, Universidade do Minho, Campus de Azurém, Guimarães, Portugal. Tel.: +351 253510 561; Fax: +351 253510569. E-mail: j.sarmento@geografia.uminho.pt

3 Tradução do autor. 
de informação. Numa economia global, argumenta HALL, as cidades competem abertamente de forma a atraírem turistas, negócios e residentes, sendo que, neste processo, a qualidade de vida, se torna crucial. O livro inclui também 85 figuras, desde quadros, fotografias, pinturas e desenhos que enriquecem em muito todos os textos.

As perguntas que este livro coloca, e que são retorquidas de várias formas, sempre brilhantemente, incluindo diversos exemplos, pormenorizadamente bem fundamentados, são sintetizadas por Hall no início do livro: Porque é que as cidades têm belles époques? Como é que estas surgem? Porque é que a chama criativa arde de forma tão especial nas cidades e não nos espaços rurais? O que torna uma cidade específica, numa época singular, tão criativa e excepcionalmente inovadora? Porque é que este espírito floresce durante alguns anos (geralmente uma década ou duas no máximo, demonstra HALL) e depois entra em declínio de forma tão súbita como quando emergiu? Porque é que existem tão poucas cidades que viveram mais do que uma época dourada? Porque é que estas mesmas cidades fracassam na recaptura da ignição criativa que outrora as animou? Sem dúvida que é um desafio vasto responder a tão profundo leque de questões.

No primeiro livro, com uma abordagem clássica, HaLL vai revelando as características comuns de um grupo de cidades: as transformações económicas e sociais rápidas, as novas formas de organização económica, a existência de riqueza individual e em alguns casos de mecenato, a condição de atractividade do talento, e a existência de tensões entre forças radicais e conservadoras. Para as cidades palcos de inovações tecnológicas - Manchester, Glasgow, Berlim, Detroit, Palo Alto e Tóquio (segundo livro) - a explicação do sucesso encontra-se nas iniciativas locais, nas inovações individuais, no êxito de outsiders, na presença de fortes redes locais, e na existência de um intenso clima de inovação. Se bem que possamos distinguir, por um lado, um ambiente de laissez faire caracterizado por iniciativas bottom-up das cidades americanas e, por outro, um capitalismo alemão ou japonês guiado pelo Estado, estas cidades caracterizam-se por não se circunscreverem geograficamente aos centros de decisão global, nem por pertencerem a periferias vincadas, sendo todas exemplos de sociedades abertas onde existem mercados locais de certa dimensão.

O livro três, que Hall constrói com o objectivo de fazer a ligação entre a inovação tecnológica e a organização urbana, analisa as cidades de Los Angeles e Memphis. Estas viveram as suas 'idades de ouro' em torno da produção em massa da cultura - a primeira apoiando-se na indústria cinematográfica e na criação de sistemas de estúdios que em muito contribuíram para a descentralização da região; a segunda baseando-se na proliferação da música afro-americana e na sua miscigenação com a cultura ocidental dominante. Em ambas as cidades, as indústrias culturais permaneceram únicas, tendo emergido em lugares consideravelmente remotos. Esta parte da obra, para além de desequilibrada em termos de fôlego e de exemplos, revela uma incapacidade em articular o sucesso de Los Angeles e Memphis com as características de sucesso análogas a outras cidades que atravessaram épocas douradas. Este ponto ilustra uma das falhas de Cities in Civilization, pois é um equívoco tentar encontrar ou sintetizar todas estas páginas e séculos de evolução urbana num conjunto restrito de pontos comuns de uma teoria ou modelo de inovação urbana. Tal esforço seria hercúleo, pois 2.500 anos de história urbana de criatividade dificilmente se resumem a meia dúzia de traços universais.

No quarto livro, HALL aborda a organização urbana, em estreita relação com a qualidade de vida. Ilustra a forma como as cidades têm garantido necessidades básicas - o fornecimento de água, o tratamento de resíduos, a eficiência do tráfego, o controlo do crime e da pobreza, sendo que a partir de um certo patamar de dimensão urbana, estas matérias se tornaram significativamente complexas (Roma foi a primeira cidade a ultrapassar este limiar). HALl mostra como a óbvia aliança da engenharia com a legislação 
- construção de aquedutos, esgotos e metropolitanos, asilos, bairros operários e cadeias revela uma divisão profunda de opiniões sobre a forma 'correcta' de viver nas cidades.

O livro cinco é uma reflexão sobre o futuro das cidades, das cidades globais e do impacto das tecnologias de informação nas cidade-região. HALl observa que as cidades bem sucedidas no passado, ou o foram por terem sido incubadoras culturais, como Atenas ou Florença, ou como inovadoras tecnológicas, como Manchester, Detroit ou Sillicon Valley. Tenta-se mostrar como a civilização embocou hoje num 'casamento entre a arte e a tecnologia', sendo que a síntese entre estas duas componentes vai ter lugar em cidades invariavelmente de grande dimensão. A pergunta que desponta é onde estão os techno-bohos?, sendo que estamos, na opinião de HALL, à beira de uma nova época dourada.

Pela sua abrangência histórica, pela profundidade e detalhe de análise fornecida, e sobretudo pela elegância e mestria como HaLl se move de cidade em cidade, de século em século, com igual entusiasmo a analisar Picasso e Roma, este é um livro comparável por certo a The City in History de Lewis Mumford. No entanto, ao contrário da visão eloquente e apaixonada, mas certamente pessimista e derrotista de MuMForD (herdada da concepção orgânica das cidades-mundiais de Patrick Geddes), Hall traz-nos uma perspectiva positiva e optimista do fin-de-siècle. Em Cities in Civilization há um claro travo que mostra que as grandes cidades são centrais para a evolução civilizacional, pois pela sua dimensão e complexidade são o lugar natural e o milieu da inovação. As épocas douradas vão continuar a emergir, e a centralidade cultural das cidades vai continuar a intensificar-se, apesar do sucesso das tecnologias de comunicação que 'conquistam' o espaço e que aparentemente iriam tornar a cidade obsoleta. Esta é uma obra indispensável a todos os que se interessam pela história e geografia das cidades, pelo urbanismo, pela sociologia urbana e pelo papel da inovação na evolução civilizacional. 